\title{
CRISIS DEL SISTEMA MIGRATORIO Y SEGURIDAD EN LAS FRONTERAS NORTE Y SUR DE MÉXICO
}

\author{
Daniel Villafuerte Solís ${ }^{1}$ \\ María del Carmen García Aguilar ${ }^{2}$
}

\begin{abstract}
En este artículo se analizan las implicaciones de la crisis del sistema migratorio Centroamérica-México-Estados Unidos, que se evidenció con la llamada crisis humanitaria de los niños migrantes mexicanos y centroamericanos detenidos por la Patrulla Fronteriza. Una de las consecuencia ha sido el reforzamiento de las fronteras sur y norte de México para detener el flujo de migrantes, y para lo ello los gobierno de México, Guatemala, Honduras y El Salvador, en estrecha colaboración con la Casa Blanca, han diseñado diversas estrategias, que van desde el incremento de la vigilancia de los pasos fronterizos, contención y deportación de migrantes, hasta la implementación de la Alianza para la Prosperidad en el Triángulo Norte de Centroamérica.
\end{abstract}

Palabras clave: crisis humanitaria, migración centroamericana, seguridad nacional, frontera sur.

\section{Introducción}

Sin lugar a duda, 2014 fue un año clave para el análisis del vínculo entre migración y fronteras, en particular en las fronteras norte y sur de México. La llamada crisis de los niños migrantes en la frontera sur de los Estados Unidos de América del Norte vino a mover varias piezas que se articulan en torno a la migración internacional, en particular el tema de la seguridad nacional, asociado con el reforzamiento de las fronteras y el endurecimiento de la política de contención de la migración.

1 Profesor-Investigador del Centro de Estudios Superiores de México y Centroamérica - UNICACH, San Cristóbal de Las Casas, México.

2 Investigadora-docente del Centro de Estudios Superiores de México y Centroamérica - UNICACH, San Cristóbal de Las Casas, México. 
La crisis de los niños migrantes dejó al descubierto el verdadero rostro de la política migratoria de Estados Unidos y de la generosa colaboración de los gobiernos de México y de los países del Triángulo Norte centroamericano (Guatemala, Honduras y El Salvador), que se revela en el incremento de las deportaciones vía aérea y terrestre desde la Unión Americana y México, respectivamente, así como en el reforzamiento de la vigilancia fronteriza en el norte $y$ en el sur.

En el norte, el gobierno de Barack Obama dictó medidas para endurecer la frontera, entre otras el aumento del presupuesto para la Patrulla Fronteriza ${ }^{3}$, la construcción de muros físicos y virtuales, así como el incremento de aviones no tripulados (drones). En el sur se incrementó el control de los llamados pasos ciegos y oficiales a lo largo de la línea fronteriza, también se creó el Centro de Administración Integral al Tránsito Fronterizo en el municipio de Playas de Catazajá, que fungirá como un centro de control en la zona norte de Chiapas, importante corredor migratorio de centroamericanos a Estados Unidos. También destaca la presencia de elementos de la gendarmería nacional, policía federal recién creada.

Así mismo, a lo largo de llamada frontera vertical (que se extiende a lo largo del país) fueron reforzados los puestos de revisión, y como un hecho inédito destacan las redadas en "La Bestia" - el tren de carga utilizado por los migrantes centroamericanos para transportarse hasta la frontera con Estados Unidos - a fin de detenerlos y deportarlos; también se pidió a la empresa ferrocarrilera que aumente la velocidad de los trenes con el fin de que los migrantes desistan en su intento de subir al tren. Humberto Mayans, coordinador para la Atención Integral de la Migración en la Frontera sur de México $^{4}$, declaró a finales de agosto: "en este momento ya son más de 6,000 migrantes irregulares que han sido bajados del ferrocarril, respetando su dignidad, con todo el respeto a sus derechos humanos, para evitar que sigan usando el ferrocarril y sigan poniendo en riesgo sus vidas" ${ }^{\prime \prime}$. Esto ha llevado a que los migrantes busquen nuevas rutas para llegar al norte ${ }^{6}$.

En este contexto, la frontera sur de México se convierte en un centro neurálgico donde se ensayan las políticas de seguridad nacional elaboradas en

3 El presupuesto a la Patrulla Fronteriza para el año fiscal 2014 ha sido el más alto de la historia con $\$ 3,634,855$ (consúltese: <http://www.cbp.gov/sites/default/files/documents/BP\%20Budget\%20 History\%201990-2014_0.pdf>), y el número de agentes reportados para el mismo año fue 20.866.

4 Esta Coordinación se creó por decreto presidencial publicado en el Diario Oficial de la Federación el día 8 de julio de 2014.

5 MAYANS, Humberto. Unos 6,000 migrantes han sido bajados del tren "La Bestia" en México".

6 MARTíNEZ, Fabiola. "Bajó más de 30\% la cifra de migrantes que requirieron apoyo del INM en su paso a EU". 
colaboración con el gobierno de Estados Unidos. Este breve artículo pretende dar cuenta del significado de la frontera sur de México desde una perspectiva geopolítica, a partir del fenómeno migratorio centroamericano que, pese a las medidas punitivas aplicadas hasta el 2014 , no se ha detenido.

\section{La frontera sur de México y su significado geopolítico}

La línea fronteriza del sur de México abarca una franja que aproximadamente 1.139 kilómetros, que se extiende a lo largo de las entidades federativas de Chiapas, Tabasco, Campeche y Quintana Roo que comparten con Guatemala y Belice. La mayor parte de esta extensión es compartida entre Guatemala y México, con una extensión de 963 kilómetros, el resto corresponde a Belice y México.

El gobierno mexicano estima que por la frontera sur de México "entran cada año en promedio 1.700.000 personas, en su mayoría visitantes y trabajadores locales, así como migrantes en tránsito que buscan llegar a los Estados Unidos" ${ }^{7}$. En 2013, el Instituto Nacional de Migración ${ }^{8}$ estimó una entrada de 1.748.475 personas en los cruces de las entidades de Chiapas, Campeche y Tabasco.

Los migrantes en tránsito aumentaron sensiblemente a partir de la década de 1990, con los acuerdos de paz en la región centroamericana y con la puesta en vigor de las políticas del Consenso de Washington. Los datos sobre deportaciones del INM revelan la importancia que van adquiriendo los flujos migratorios centroamericanos: "En 1980 la cifra de deportados rebasó las 10 mil personas y en 1990 sobrepasó las cien mil anuales, cifra que continuó hasta 1999, al registrarse un total de 123.680 personas devueltas" ${ }^{\prime \prime}$.

A partir del año 2001 el número de detenciones de migrantes se incrementó notablemente, alcanzando en este año la cantidad de 150.530, en los años posteriores se observa un aumento sostenido hasta llegar en 2005 a la cifra de 240.260. La mayoría de los migrantes detenidos provienen del Triángulo Norte de Centroamérica. A partir de 2006 comienza a disminuir la cantidad de migrantes detenidos, registrándose las cifras más bajas en los años 2007, 2008 y 2009, cuando la crisis económica en Estados Unidos alcanza su nivel más alto: para estos años las cantidades son 51.700; 39.436; y 64.447, respectivamente.

En 2012 las cifras de deportados (devueltos en la terminología del INM) repuntan sustancialmente, alcanzando para este año 76.840 y para el año

GOBIERNO FEDERAL. Informe del Estado mexicano sobre secuestros, extorsiones y otros delitos cometidos contra personas migrantes en tránsito por territorio mexicano, p. 11.

8 INSTITUTO NACIONAL DE MIGRACIÓN (INM). Boletín Mensual de Estadísticas Migratorias 2013.

9 CONAPO. Migración internacional en la frontera sur de México, p. 2. 
siguiente suman 77.216 migrantes. De acuerdo con el gobierno de Guatemala ${ }^{10}$, para 2014 se alcanzó la cifra de 112.842 para los tres países referidos, la cifra más alta correspondió a Honduras, con 45.613, ligeramente por arriba de Guatemala. En otra palabras, el incremento de deportados en 2014 fue de 75 por ciento con relación al año 2009 y de 186 por ciento respecto al año 2008, en el momento más álgido de la crisis económica en Estados Unidos.

La disminución del flujo migratorio entre 2006 y 2011, que se expresa en una baja en el número de detenciones se explica - según la versión oficial - por la crisis económica y el desempleo en Estados Unidos. Sin embargo, es necesario agregar dos factores de relevancia: por una parte, el blindaje de la frontera vertical en México y las medidas de reforzamiento de la frontera con Estados Unidos, y por otra, el alarmante incremento de la violencia hacia los migrantes de paso por México que se ha traducido en extorsiones, secuestros, violaciones, torturas y asesinatos.

Las estadísticas de detenciones y deportaciones, tanto en México como en Estados Unidos revelan parcialmente la magnitud del problema. La Patrulla Fronteriza reporta que el número de detenciones de migrantes irregulares ha venido descendiendo de un millón 89 mil en 2006, previo a la crisis, a 556.041 en 2009, entre el 90 y 92 por ciento de las detenciones son de mexicanos, el resto son predominantemente de origen centroamericano. Este descenso relativo se explica por la disminución del flujo migratorio que entre 2007 y 2009 cayó a un promedio anual de 150.000 migrantes frente a un promedio de 500.000 durante el periodo 2000-2005. Sin embargo, las detenciones son mayores en proporción a la baja del flujo migratorio, lo que revela mayor activismo de la Patrulla Fronteriza y endurecimiento de la política de seguridad del gobierno norteamericano.

Para los migrantes centroamericanos la frontera sur de México representa el mayor reto para llegar a la Unión Americana. Es una frontera que pasó de ser, desde mediados de los noventa del siglo XX, justo cuando la región comenzaba un proceso de transición a la democracia, espacio de refugio a muro de contención, con un enorme costo en materia de derechos humanos.

En esta frontera prácticamente se inicia el viaje más incierto en la vida del migrante: "No se sabe con certeza cómo será la azarosa ruta hacia el Norte, la fiabilidad de un coyote $y$, de lograr llegar, conseguir un trabajo en Estados Unidos. La migración también es un coctel de fe, terquedad y suerte"11. A pesar de todo, la migración hacia Estados Unidos sigue siendo el camino preferido

\footnotetext{
${ }^{10}$ Dirección General de Migración, puede consultarse la sección de estadísticas en: < http://www. migracion.gob.gt/>.

11 RAMÍREZ, Sigfredo. "Retrato de una migración".
} 
de los jóvenes centroamericanos. No han importado las medidas de seguridad impuestas por los gobiernos de México y Estados Unidos, no han importado los peligros que asechan en el camino, no han importado las extorsiones, los secuestros y tampoco los asesinatos, como tampoco importarán las medidas que seguirá implementando los gobiernos por venir.

Desde hace 15 años, el tema de la frontera sur ha sido una preocupación del gobierno mexicano, desde el presidente Vicente Fox, luego con Felipe Calderón y ahora con Peña Nieto. Esta preocupación deriva del nuevo contexto de relaciones internacionales, en particular de la política del gobierno de la Casa Blanca en materia de terrorismo, narcotráfico y migración.

Antes del 2000 se instrumenta el programa "Sellamiento de la Frontera Sur". Poco después, cambia de nombre a Plan Sur, que coincide con dos eventos geopolíticos de relevancia: 1) el anuncio del proyecto Plan Puebla-Panamá en $2001 ; 2)$ los atentados del 11 de septiembre de 2001. Derivado de estos últimos, en 2002 México firma con el gobierno de Estados Unidos un acuerdo sobre fronteras inteligentes, en el que se compromete a redoblar la vigilancia en la frontera sur de México. En el mismo año los gobiernos de México, Belice y Guatemala suscriben un acuerdo con el que se crea el Grupo de Alto Nivel para la Seguridad Fronteriza (GANSEF).

En diciembre de 2008, los presidentes Felipe Calderón y George Bush firman la Iniciativa Mérida, mediante este instrumento el gobierno de Washington se compromete a aportar financiamiento, equipo y capacitación a México en materia de seguridad.

En mayo de 2011, la Conferencia Nacional de Gobernadores (CONAGO) de México solicita al gobierno federal el despliegue de fuerzas federales a lo largo de la frontera sur. Los gobernadores solicitaron la integración de una coordinación regional, con participación de los tres órganos de gobierno, para el diseño de estrategias de combate a la delincuencia, el establecimiento de pasos migratorios formales y la depuración del INM. Exhortaron al Congreso de la Unión para agilizar la discusión y aprobación de las reformas a la Ley de Seguridad Pública Nacional, en lo referente a la creación de la policía Fronteriza.

En julio de 2012, el presidente guatemalteco, Otto Pérez Molina, refirió que

la seguridad en la frontera es un esfuerzo conjunto y Guatemala ha propuesto la creación de nuevas rutas que beneficien a todo el país y que minimicen la porosidad de la frontera... Comenzaremos una operación combinada donde las fuerzas de Guatemala y Estados Unidos realizarán operativos de investigación y ataque frontal en los puntos fronterizos que permitan disminuir el porcentaje de narcotráfico y de droga que transita en el país ${ }^{12}$.

12 "Prepara Guatemala Acciones de Seguridad en la Frontera". 
En marzo de 2013 los senadores de la Comisión de Asuntos Fronterizos Sur y la embajada de Guatemala en México coincidieron en la urgencia de impulsar un plan maestro que articule el desarrollo de la región sur-sureste y la integración de nuestro país con Centroamérica. El 3 de junio del mismo año el secretario de Gobernación, acompañado de los gobernadores de Chiapas, Campeche, Tabasco y Quintana Roo, y el primer círculo del gabinete de seguridad, refirió que la frontera sur estará bajo el resguardo de la secretaria de Marina. Dijo que el objetivo es evitar el paso libre que se da por integrantes de la delincuencia, quiénes entran, quiénes sales, a qué vienen, son temas de seguridad de México, que también tiene que ver con los países de Centroamérica.

En mayo de 2013 el comandante del Ejército Sur de Estados Unidos visitó las instalaciones donde funcionará la Fuerza de Tarea en San Marcos: anunció la donación de 42 vehículos tácticos, y 5 camiones Hino para el control fronterizo. En julio del mismo año se oficializa la creación del grupo interinstitucional Fuerza de Tarea en la frontera Tecun-Uman, en Guatemala.

El 24 de marzo de 2014 fuentes de la Comisión Nacional de Seguridad de México anunciaron la puesta en marcha de cinturones de contención terrestre y marítima. Precisaron que habrá conexiones o nodos carreteros y vigilancia especial en puntos costeros. Un primer cinturón abarca zonas de Huixtla, Suchiate, Arriaga. Un segundo cinturón de seguridad en la Trinitaria, Comitán, Benemérito de las Américas y Palenque, ambos en el estado fronterizo de Chiapas; y un tercero en el Istmo, con áreas específicas en Las Choapas y Cosoleacaque, Veracruz.

Desde abril de 2014 sonaron las alarmas sobre la migración de niños mexicanos y centroamericanos, que hacia la segunda mitad del mes de junio adquirió un carácter crítico. Varios periódicos en el mundo, en México y en Estados Unidos, mantuvieron al menos hasta el mes de octubre el tema migratorio en sus primeras planas. El diario The New York Times publicó diversos artículos y editoriales pidiendo a Obama que pare las deportaciones. En junio del mismo año Peña Nieto llamó por teléfono a Barack Obama para conversar sobre el problema de los niños migrantes, y acordaron enviar a Guatemala el secretario de Gobernación, Miguel Ángel Osorio Chong, y el vicepresidente Joseph Biden, con el objetivo de diseñar una estrategia regional conjunta con las naciones de América Central.

En el marco de la crisis que presenta el sistema migratorio CentroaméricaMéxico-Estados Unidos, el 27 de junio de 2014 el embajador de Estados Unidos, Anthony Wayne, visitó la frontera sur. Se reunió con el gobernador de Chiapas y miembros de su gabinete, y expresó que "Ios esfuerzos de Chiapas tendrán un impacto significativo sobre la seguridad y prosperidad de los Estados Unidos, 
que está listo para trabajar en conjunto para hacer frente a los retos compartidos y tomar las oportunidades también compartidas"13. El embajador Wayne se entrevistó con funcionarios del INM y visitó la estación migratoria Siglo XXI. Se mencionó que para reforzar la seguridad de la frontera sur Estados Unidos ha invertido 3.5 millones de dólares, en el marco de la Iniciativa Mérida.

El 7 de julio de 2014, el secretario de Seguridad Nacional, Jeh Johnson, aseguró que "la frontera estadounidense no está abierta a la inmigración ilegal". Al mismo tiempo, el congresista demócrata por el estado de Texas, Henry Cuellar, indicó que solo en el mes de mayo los agentes detuvieron en la frontera de Texas a 48 mil personas, de las cuales 9,700 eran niños que viajaron sin compañía de sus padres. Este mismo día, el presidente Obama anunció que pediría al Congreso 3,800 millones de dólares que ayudará a incrementar la detención, atención y transporte de niños migrantes.

En el marco de la crisis migratoria y de fronteras, el 8 de julio de 2014, Peña Nieto, en compañía de los gobernadores de Chiapas, Campeche, Quintana Roo y Tabasco, y del presidente de Guatemala, inauguró el Centro de Administración Integral al Tránsito Fronterizo, ubicado en el municipio de Playas de Catazajá, Chiapas. Allí mismo esbozó el Plan Sur que consta, entre otros, de los siguientes puntos: 1) instalación de cinco nuevos centros de seguridad; 2) mejorar los recursos de los pasos aduanales en las fronteras de México, 10 en Guatemala y 2 en Belice; 3) aumento de unidades médicas en la zona; 4) creación de la Coordinación Integral de la Frontera Sur que dependerá de la Secretaría de Gobernación. Como se puede ver, este Plan sur es una reedición, con el mismo nombre, del puesto en marcha con Vicente Fox, es decir, sellar la frontera sur.

En la parte blanca del Plan Sur figura el programa Paso Seguro para fortalecer los albergues por la vía institucional, otorgar tarjetas de trabajador fronterizo y tarjetas de visitante regional a ciudadano de Guatemala y Belice, nada nuevo, se había instituido desde 2008.

\section{Cambios en la política migratoria y la crisis de los niños migrantes}

En la historia reciente de la frontera sur hay tres momentos significativos que marcan el quehacer del Estado mexicano. El primero es el de la guerra civil en Centroamérica, sobre todo en Guatemala, que provocó el éxodo de miles de refugiados a territorio mexicano. Al inicio de los años ochenta del siglo XX el gobierno de México enfrentó una realidad sin tener una idea precisa de lo que significaba la conflictividad político-militar en el vecino país de Guatemala para las relaciones fronterizas. Volver la mirada a la frontera sur significó reconocer la ausencia de una política fronteriza y la importancia que en ese momento podría

\footnotetext{
13 "EU reforzará medidas antimigratorias en el sur de México".
} 
significar la presencia de hasta 120 mil refugiados, en un contexto de enorme presión internacional en materia de derechos humanos.

El segundo momento se refiere a los atentados del 11 de septiembre de 2001 en Estados Unidos, que generó una serie de medidas de resguardo fronterizo y endurecimiento de la vigilancia y control del tránsito de personas no sólo en la frontera México-Estados Unidos, sino también en la frontera sur de México. En la práctica se opera un corrimiento de la frontera norte hacia el sur (del río Bravo al río Suchiate) donde se cree que se generan amenazas a la seguridad nacional de Estados Unidos. Poco antes de estos acontecimientos se había implementado el programa denominado "sellamiento de la frontera sur" que luego fue sustituido por el Plan Sur.

Los atentados del 11 de septiembre tendieron a reforzar las acciones del Plan Sur. En marzo de 2002 el gobierno de Estados Unidos establece el acuerdo con México sobre "fronteras inteligentes", que implicó 22 compromisos específicos para reforzar la vigilancia en su frontera sur. En particular, el que se refiere a "fronteras seguras y disuasión a traficantes de personas". Como hemos apuntado líneas arriba, en junio de 2002 se crea el GANSEF.

Con fecha 12 de marzo de 2008, la Secretaría de Gobernación anuncia reformas para trabajadores y visitantes en la frontera sur. La nueva forma migratoria para trabajadores tiene un año de vigencia para laborar en cualquier actividad lícita, siempre que exista una oferta de trabajo. Los requisitos para obtener la Forma Migratoria para Trabajadores Fronterizos (FMTF) son: ser nacionales guatemaltecos o beliceños, tener 16 años o más, contar con una oferta de trabajo lícita y honesta previa por parte del empleador mexicano en las entidades de Chiapas, Quintana Roo, Tabasco y Campeche, no tener antecedentes penales. La idea es favorecer la circularidad "positiva" de la migración.

Por su parte, el gobierno de Chiapas creó el 5 de junio de 2008 la Fiscalía Especializada en Delitos Cometidos en Contra de los Inmigrantes. De acuerdo con la propia dependencia, su misión consiste en "defender los derechos de los inmigrantes y transmigrantes en el Estado, en donde se procurará justicia a través de la figura del Ministerio Público".

En octubre de 2008 el gobierno de Chiapas crea la Comisión Intersecretarial para la Atención de los Asuntos de los Trabajadores Migrantes en la que participan doce dependencias en cinco grupos de trabajo: certeza jurídica y justicia laboral; seguridad y previsión; educación; promoción del desarrollo; e integración de la información.

El 23 de junio de este año 2009 el gobierno de Chiapas y la Organización Internacional para las Migraciones (OIM) firmaron un convenio de colaboración denominado "Unidos para el respeto de los Derechos de los Migrantes". El 
mismo día la OIM abrió una oficina en la ciudad de Tapachula, puerta principal de entrada a Centroamérica.

En resumen, el gobierno de México aplica una política migratoria que se expresa en dos medidas: por una parte, impide la entrada de transmigrantes irregulares mediante medidas de control policiaco en las rutas migratorias y refuerza la vigilancia en las fronteras; por otra parte, se intenta regular los flujos documentados que se dirigen al mercado laboral de las zonas fronterizas de Chiapas y otros estados de la república mexicana. En concordancia con esta política de doble rasero, el gobierno de Chiapas creó a principios de 2007 la policía estatal fronteriza y, por otra parte, implementa medidas para atender los asuntos laborales de los trabajadores fronterizos.

Para reforzar la primera medida antimigrante, los gobiernos de México y Estados Unidos suscriben la llamada Iniciativa Mérida. Se trata de un paquete de ayuda económica, técnica y de inteligencia del gobierno de los Estados Unidos para combatir el crimen organizado, que incluye a la migración transnacional. La propuesta, derivada del encuentro entre los presidentes Bush y Calderón en Mérida, Yucatán, a medidos de 2007, fue presentada a la Cámara de Representantes de los Estados Unidos el día 13 de mayo de 2008. El día 26 de junio el Senado de ese país aprobó la Iniciativa por mayoría de 92 votos, sólo 6 legisladores votaron en contra. La asignación presupuestal para el año fiscal 2008 fue de 400 millones de dólares.

La Iniciativa generó diversas reacciones: unas en el sentido de que tal proyecto significaba la articulación con el Plan Colombia; otras, fundamentalmente por parte del gobierno de México, en el sentido eliminar las salvaguardas en materia de derechos humanos. Y es que la propuesta original contenía el "requerimiento de investigar alegatos de violaciones de garantías individuales cometidas por cualquiera que reciba asistencia de la Iniciativa Mérida".

La intensidad de la migración centroamericana de paso por México ha dado lugar a la extorsión, a la detención ilegal, el abuso sexual y el asesinato: el 9 de enero de 2009 tres migrantes fueron asesinados y ocho resultaron heridos de bala por agentes de la Policía Estatal Preventiva de Chiapas, quienes dispararon a una camioneta que transportaba migrantes de El Salvador, Honduras, Guatemala, Ecuador y China. En el vehículo viajaban varias personas, entre 26 y 40 , resultando muertas dos ecuatorianas y un guatemalteco.

El gobierno ecuatoriano envío al gobierno mexicano una nota de protesta y la Comisión Nacional de los Derechos Humanos $(\mathrm{CNDH})$ inició un queja de oficio, en un comunicado esta institución expresó: "Para este órgano nacional de defensa de los derechos humanos, resulta inadmisible que los cuerpos de seguridad pública actúen de manera arbitraria y hagan uso excesivo de la fuerza 
sin el menor reparo por los derechos humanos y fuera del orden que estipula el estado de derecho"114.

La amenaza que cae sobre los transmigrantes no sólo proviene del ejército y de las policías federales, estatales y municipales, sino también de bandas organizadas que controlan las vías por donde transitan los migrantes. Antes de que el huracán Stan destruyera las vías férreas y los puentes en 2005, las pandillas Mara Salvatrucha (MS-13) y Barrio 18 (B-18) ya controlaban el tráfico de indocumentados a bordo del tren que partía de Ciudad Hidalgo, en la frontera con Guatemala, hasta el norte de México.

Diversas denuncias, sobre todo por parte de la Iglesia católica, han señalado el peligro que corren los migrantes centroamericanos en la llamada "Ruta del migrante", donde se incluye preponderantemente Chiapas, Oaxaca, Veracruz y Tabasco, sin dejar de considerar a Tamaulipas, lugar donde en el año 2008 fueron efectuadas poco más de 4 mil detenciones, el 10.2 por ciento del total nacional.

La Comisión Nacional de Derechos Humanos, en su registro Nacional de Agresiones a Migrantes reportó 45 agresiones en los últimos 20 días de 2008, en la ruta del migrante del tramo Chiapas. La mitad de estas agresiones fueron llevadas a cabo en la localidad de Huixtla, en el sitio conocido como "La Arrocera", que ya tiene fama internacional por el número de asaltos, robos y asesinatos de migrantes.

Los niveles de violencia contra los migrantes centroamericanos llegaron a tal punto que el Comité de Familiares de Migrantes Fallecidos o Desaparecidos de El Salvador (Cofamide) decidió en 2009 llevar a cabo la llamada Caravana de la Esperanza para visitar la ruta de los migrantes, en particular Chiapas y Oaxaca $^{15}$. De acuerdo con la Cofamide, 293 salvadoreños habían desaparecido o muerto en Chiapas, Tabasco, Veracruz y Oaxaca. Estos territorios conforman, según los migrantes salvadoreños, el embudo de la muerte y quien logra cruzarlo prácticamente ya está en Estados Unidos ${ }^{16}$.

La industria del secuestro se ha extendido a los sectores sociales más vulnerables, como son los transmigrantes cuya desprotección de los gobiernos

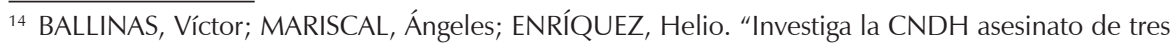
migrantes en Chiapas".

${ }^{15}$ La Caravana como tal nació en 2004. Martha Sánchez, Presidenta del Movimiento Migrante Mesoamericano relata que "unos 70 mil migrantes provenientes de Centro y Sudamérica han desaparecido en su paso por México hacia Estados Unidos", entrevista realizada por Carmen Aristegui, 12 de diciembre de 2013, disponible en: < http://aristeguinoticias.com/1212/mexico/ han-desaparecido-70-mil-migrantes-en-transito-por-mexico-martha-sanchez-soler-en-cnn/> . Consultado: 20.02.2014.

${ }^{16}$ MARISCAL, Ángeles. "En dos años, 293 salvadoreños han muerto o desaparecido en México". 
de sus respectivos países, así como los de tránsito, es prácticamente nula. El grado de indefensión es de tal magnitud que pone en grave riesgo la vida del migrante. En 2009, la Comisión Nacional de Derecho Humanos de México $(\mathrm{CNDH})$ publicó un informe que cubre un periodo de seis meses (septiembre de 2008 a febrero de 2009).

En este informe por primera vez se hacen revelaciones sustentadas en estadísticas y testimonios, que dejan al descubierto la magnitud del problema. El citado informe refiere: "se obtuvo información que indica que el número de migrantes que fueron víctimas de privación de su libertad fue de 9,758 personas, es decir, más de 1,600 secuestrados por mes". Los datos del informe son reveladores de la magnitud del problema que contrasta notablemente con el discurso oficial en lo que se refiere a la protección de migrantes. De hecho, la $\mathrm{CNDH}$ señala la participación de altas autoridades en los actos delictivos contra los migrantes.

Un tercer momento se refiere a la crisis de los niños migrantes de mediados de 2014, que revela la profundidad del colapso del sistema migratorio Centroamérica-México-Estados Unidos. Esto ocurre cuando se pensaba, y así se manejó, sobre todo después de la crisis económica y financiera de Estados Unidos, que la migración de centroamericanos y mexicanos se había autolimitado, al grado que, en el caso de México, se hablaba de un saldo migratorio cercano a cero que se explicaba, según las autoridades mexicanas, por un mejoramiento de las condiciones económicas y de empleo en el país.

¿Cómo está "resolviendo" el gobierno de Obama la crisis migratoria? La decisión más importante fue trasladar a México y a los países centroamericanos, principalmente a Guatemala, El Salvador y Honduras, la responsabilidad primordial de restringir el paso de migrantes. México respondió prontamente y creó la Coordinación para la Atención Integral de la Frontera Sur, organismo desconcentrado de la Secretaría de Gobernación, para articular los esfuerzos de las dependencias federales con organismos estatales y municipales.

Aunque la migración fue un tema destacado en las metas del segundo periodo de gobierno del presidente Barack Obama, que inició en enero de 2013. Aun año y medio de distancia la promesa de reforma migratoria fue declarada muerta oficialmente. Esta reforma que fue promesa de campaña en el primer periodo de gobierno y meta destacada en el segundo, se obstaculizó por los republicanos de la cámara de representantes. A este hecho la administración de Obama, a contrapelo de su discurso, fue radicalizando acciones antimigrantes, que se expresaron en deportaciones masivas de centroamericanos que alcanzaron niveles históricos en 2013 y 2014. En este contexto, durante el 2014 se mantuvo una política de "tierra arrasada" con los migrantes, llevando a la 
detención de 68 mil menores centroamericanos y mexicanos, que desbordó la capacidad de los centros de detención que mostró el quiebre del sistema migratorio y una crisis humanitaria, reconocida por el propio Obama. La crisis ha sido de tal magnitud que el gabinete de seguridad del gobierno norteamericano ha tomado cartas en el asunto haciendo diversas consultada a los gobiernos de México y Centroamérica.

El año 2014 cerró con el viaje de Jeh Johnson, Secretario de Seguridad Interna, el 16 de diciembre, que por tercera ocasión estuvo en México para entrevistarse con el presidente Peña Nieto y el secretario de Gobernación. Esta vez lo hizo acompañado de Rand Beers y Alan Bersin, asistente del presidente en materia de seguridad nacional y subsecretario de Asuntos Internacionales y Jefe Diplomático del Departamento de Seguridad Nacional, respectivamente.

En la reunión con el presidente mexicano estuvieron presentes, además de los funcionarios referidos anteriormente, oficiales del Departamento de Seguridad Nacional y Anthony Wayne, embajador de Estados Unidos en México. Este encuentro ocurre en vísperas de la visita de Peña Nieto a Estados Unidos programada para el 5 de enero, con el propósito de "hablar sobre las acciones ejecutivas que dictó el Presidente Obama el 20 de noviembre con el fin de arreglar el sistema migratorio en Estados Unidos. Hay mucho interés en estas acciones ejecutivas por parte del gobierno de México", reveló una nota de la embajada de vecino país en México ${ }^{17}$.

En el marco de la crisis del sistema migratorio, los migrantes centroamericanos enfrentan el más violento embate que se tenga memoria por parte de las autoridades mexicanas. En este sentido, un diario salvadoreño refiere que "agentes de la policía federal mexicana y empleados del servicio de inmigración en el sur de México han comenzado a registrar a fondo la ruta del infame tren de carga conocida como La Bestia, retirando a migrantes de los vagones y enviándolos a centros de deportación"18.

El gobierno de Barack Obama está preocupado, no tanto por los niños migrantes sino por las implicaciones políticas que encierra este fenómeno que cuestiona el discurso a favor de los migrantes, que además había prometido, por segunda ocasión, sacar adelante la reforma migratoria. En esta preocupación ha movido todas las piezas a su alcance, es decir haciendo partícipes de la responsabilidad a los gobiernos de Guatemala, Honduras, El Salvador y México, todos por ser países de origen y tránsito de migrantes, incluidos a los menores de edad. Sin embargo, hasta ahora el diagnostico ha tenido un claro enfoque de

17 EMBAJADA DE ESTADOS UNIDOS EN MÉXICO. Resumen del viaje del secretario Johnson a México.

18 "México arrecia controles en ruta de migrantes centroamericanos". 
seguridad nacional, de ver la migración como un problema para Estados Unidos, diagnóstico que el resto de los países asumen. Cuando se ve la migración como problema y no como fenómeno social, las medidas de intervención llevan un sesgo muy particular que quedan muy claras en parte del siguiente texto publicado por la Procuraduría General de la República de México:

El día de hoy se reunieron en la Ciudad de México los Fiscales y Procuradores Generales de El Salvador, los Estados Unidos de América, Guatemala, Honduras y México a fin de abordar desde una perspectiva de responsabilidad compartida el fenómeno criminal que afecta a un gran número de menores migrantes no acompañados. El propósito fue acordar una estrategia para proteger su seguridad e integridad, así como perseguir de manera eficaz a las organizaciones criminales que se benefician de la comisión de la comisión de diversos delitos asociados con la migración, como la trata y el tráfico de personas (Procuraduría General de la República, boletín 159/14).

Además de las acciones adoptadas por el gobierno de México, a las que hemos referido línea arriba, destacan medidas que intentan resolver la crisis del sistema migratorio: la primera, anunciada por el presidente Obama el día 20 de noviembre, consiste acciones ejecutivas a falta de un acuerdo en la Cámara de Representes para la reforma migratoria, sancionada por el Senado en 2013. Estos resolutivos permitirían a unos 5 millones de personas trabajar por tres años sin ser deportados.

La otra medida, emulando a la Alianza para la Seguridad y Prosperidad para América del Norte (ASPAN) en la que participan México, Estados Unidos y Canadá, es la propuesta de la Alianza para la Prosperidad en el Triángulo Norte que fue presentada el 14 de noviembre de 2014 en Washington, en la sede del Banco Interamericano de Desarrollo. El propósito de esta iniciativa es combatir la pobreza y la violencia como medio para desestimular la migración y se basa en cuatro ejes: emprendimiento y creación de empleo; seguridad; capacitación técnica y fortalecimiento institucional.

EEUU se comprometió a colaborar con un monto no especificado y prometió estimular a organismos multilaterales para que brinden su ayuda y para que grandes empresas hagan inversiones estratégicas en poblados de mayor migración. Hasta ahora no existe una definición precisa de los apoyos y mecanismos concretos para operar el mencionado programa. Entre tanto, Estados Unidos deportó en 2014 a 51.951 guatemaltecos, 36.361 hondureños y alrededor de 28 mil salvadoreños, el mayor número registrado en la historia del sistema migratorio Centroamérica-Estados Unidos. 


\section{Reflexión final}

Los atentados del 11 de septiembre de 2001 marcan una nueva etapa en el tema de la seguridad mundial y nacional. El discurso del terrorismo creado y recreado por el gobierno de la Casa Blanca va alimentando una política de seguridad que se traduce en el reforzamiento y vigilancia de las fronteras, al tiempo que se renueva la vieja tesis de la seguridad nacional puesta es boga durante la llamada Guerra Fría.

Detrás de las estadísticas sobre el crecimiento de las remesas ${ }^{19}$, que los gobiernos de los países de origen de los migrantes celebran con júbilo y llegan a decir que éstas constituyen una palanca para el desarrollo, que la migración es una oportunidad, que generan capital humano. Detrás de esa visión optimista, se ocultan otros rostros: el de los desaparecidos, los secuestrados, los muertos, las extorciones, las mujeres violadas, el sufrimiento de los niños y adolescentes, los mutilados del tren. El precio que se paga por alcanzar el "sueño americano" es demasiado alto, y sin embargo la migración es un fenómeno que no termina. La migración se convirtió en un fenómeno estructural. La "causación acumulativa" convirtió la migración en un fenómeno estructural, que se consolidó con las políticas del Consenso de Washington en Centroamérica.

Las experiencias personales de migrantes deportados están llevando a relativizar el sueño americano. No obstante, la migración sigue, y seguirá hasta que las condiciones económicas, sociales y políticas en los países de origen cambien sustancialmente. Entre tanto, el sueño americano permanece en las aspiraciones de muchas familias, en los jóvenes que no encuentran opciones de empleo y de vida digna en sus lugares de origen.

\section{Bibliografía}

BALLINAS, Víctor; MARISCAL, Ángeles; ENRÍQUEZ, Helio. "Investiga la CNDH asesinato de tres migrantes en Chiapas". La Jornada, México, 13 de enero, 2009.

COMISIÓN NACIONAL DE LOS DERECHOS HUMANOS - CNDH. Informe Especial sobre los casos de Secuestros en contra de Migrantes. México, 15 de junio 2009.

CONAPO. Migración internacional en la frontera sur de México. Serie Migración Internacional, boletín n. 12, año 4, México, 2000.

Diario Oficial de la Federación. Decreto por el se crea la Coordinación para la Atención Integral de la Migración en la Frontera Sur. México: SECRETARÍA de Gobernación, 8 de Julio de 2014.

EMBAJADA DE ESTADOS UNIDOS EN MÉXICO. Resumen del viaje del secretario

${ }_{19}$ Durante el periodo 2000-2008, Guatemala, El Salvador, Honduras y Nicaragua captaron alrededor de 65 mil millones de dólares, lo que significa un incremento de 167 por ciento durante el periodo. La Inversión Extranjera Directa (IED) acumulada entre 2000 y 2007 fue de 11736 millones de dólares. 
Johnson a México. 17 de diciembre de 2014. Disponible en: <http://spanish. mexico.usembassy.gov/es/spress/resumen-del-viaje-del-secretario-johnson-amxico.html>. Consultado: 10.12.2014.

"EU reforzará medidas antimigratorias en el sur de México". Siempre, Seminario Político, versión digital, 05 de julio de 2014. Disponible en: < http://www.siempre. com.mx/2014/07/eu-reforzara-medidas-antimigratorias-en-el-sur-de-mexico/> . Consultado: 18.11.2014.

GOBIERNO FEDERAL. Informe del Estado mexicano sobre secuestros, extorsiones y otros delitos cometidos contra personas migrantes en tránsito por territorio mexicano. México, 2010. Disponible en: <https://www.google.com.mx/?gfe_rd=c $r \& e i=L$ tyqVL7yHYmFqAbPmIHQBw\&gws_rd $=s s l \# q=$ Informe + del + Estado $+m$ exicano + sobre + secuestros $\% 2 \mathrm{C}+$ extorsiones $+\mathrm{y}+$ otros + delitos + cometidos $+\mathrm{c}$ ontra + personas + migrantes + en + tr\% $3 \% \mathrm{~A} 1$ nsito + por + territorio + mexicano $>$. Consultado: 10.12.2014.

INSTITUTO NACIONAL DE MIGRACIÓN - INM. Boletín Mensual de Estadísticas Migratorias 2013. México: Secretaría de Gobernación, 2013.

MARISCAL, Ángeles. "En dos años, 293 salvadoreños han muerto o desaparecido en México". La Jornada, México, 13 de febrero 2009.

MARTÍNEZ, Fabiola. "Bajó más de 30\% la cifra de migrantes que requirieron apoyo del INM en su paso a EU". La Jornada, México, 28 de diciembre 2014.

MAYANS, Humberto. "Unos 6,000 migrantes han sido bajados del tren "La Bestia" en México". La Prensa Gráfica, 26 de agosto 2014, El Salvador. Disponible en: <http://www.laprensagrafica.com/2014/08/26/unos-6000-migrantes-han-sidobajados-del-tren-la-bestia-en-mexico >. Consultado: 30.09.2014.

"México arrecia controles en ruta de migrantes centroamericanos". elsalvador.com, 29 de agosto de 2013. Disponible en: < http://www.elsalvador.com/mwedh/nota/ nota_completa.asp?idCat $=47860 \& i d A r t=9055815>$. Consultado: 02.11.2013.

"Prepara Guatemala Acciones de Seguridad en la Frontera". El Orbe, Tapachula, México, 10 de julio de 2012.

PROCURADURÍA GENERAL DE LA REPÚBLICA. "Reunión de Procuradores y Fiscales Generales sobre el tema de tráfico de menores migrantes no acompañados". Boletín 159/14, México, 09 de septiembre de 2014. Disponible en: <http://www. pgr.gob.mx/prensa/2007/bol14/Sep/b15914.shtm> . Consultado: 28.11.2014.

RAMÍREZ, Sigfredo. "Retrato de una migración". La Prensa Gráfica, El Salvador, 28 de diciembre 2014. Disponible en: <http://www.laprensagrafica.com/2014/12/28/ retrato-de-una-migracion $>$. Consultado: 30.12.2014. 


\section{Abstract \\ Migratory system crisis and security in the northern and southern borders of Mexico}

This article analyzes implications of the current Central America-MexicoUnited States migratory crisis, evident with the so called humanitarian crisis of mexican child migrants detained by the Border Patrol. One of the consequences of this crisis has been the heightened security on Mexico's northern and southern borders to stop the influx of migrants. The governments of Mexico, Guatemala, Honduras and El Salvador, working closely with the White House have devised a series of strategies that range from increased surveillance of border crossings, containment and deportation of migrants, to implementing the Alliance for Prosperity in the Northern Triangle of Central America.

Keywords: humanitarian crisis, Central American migration, national security, southern border.

Recebido para publicación en 17.01.2015

Aceptado para publicación en 13.04.2015

Received for publication in January, 17 th 2015

Accepted for publication in April, 13 ${ }^{\text {th }}, 2015$

ISSN impresso 1980-8585

ISSN eletrônico 2237-9843

http://dx.doi.org/10.1590/1980-85852503880004406 